\title{
Accessible Website Content Guidelines for Users with Intellectual Disabilities
}

Joyce Karreman, Thea van der Geest and Esmee Buursink

Department of Professional and Technical Communication, Faculty of Behavioural Sciences, University of Twente, Enschede, The Netherlands

Accepted for publication 16 October 2006

Background The W3C Web Accessibility Initiative has issued guidelines for making websites better and easier to access for people with various disabilities (W3C Web Accessibility Initiative guidelines 1999).

Method The usability of two versions of a website (a non-adapted site and a site that was adapted on the basis of easy-to-read guidelines) was tested with two groups of 20 participants. One group had intellectual disabilities but could read, the other group had no identified intellectual disabilities. In a $2 \times 2$ experimental design, it was investigated whether the easy-to-read website was indeed better accessible and usable for the participants with intellectual disabilities.
Results The adaptation of the website worked well for participants with intellectual disabilities. Users without identified intellectual disabilities were as effective with the adapted site as they were with the non-adapted site.

Conclusion The results form an empirical basis for recommendations about applying guidelines for easy-to-read text on websites for people with intellectual disabilities.

Keywords: accessibility guidelines, easy-to-read text, quantitative experimental research, websites

\section{Introduction}

The W3C Web Accessibility Initiative (WAI) has issued guidelines for making websites better and easier to access for people with various disabilities (W3C Web Accessibility Initiative guidelines 1999). The fourteen guidelines are formulated as a set of 63 checkpoints, divided over three levels of priority. The WAI guidelines and checkpoints have gained the status of legal or formal requirements in many countries. They define target levels of accessibility, which are applied most often for sites that are produced by public organizations (such as governments or municipalities), funded with public money and/or meant to support people in their professional and occupational activities. In addition, many non-public organizations worldwide have expressed their intention to comply with the accessibility standards and aspire for the set target levels of accessibility. So, the WAI guidelines have achieved the de facto status of hallmark of accessibility.

Most of the WAI guidelines and checkpoints focus on making websites accessible and operable for users with visual and motor disabilities. They specify in detail what the accessible website should do or contain. Websites that follow the guidelines can be accessed by users of assistive and adapted devices, such as screen readers or special keyboards. The guidelines document claims to be also directed at people who have difficulty reading and comprehending text, or who are not proficient in the language in which the content of the site is presented. The guidelines, however, are much less clear regarding how to make web content accessible for those with intellectual disabilities that affect the language skills.

Checkpoint 14.1 (a highest priority level checkpoint) aims directly at making content accessible. It states: use the clearest and simplest language appropriate for a site's content. Although the intention of the checkpoint is very clear, it seems doubtful whether it helps content designers or writers deciding on what to do to make the verbal content of a website accessible for people with intellectual or language disabilities.

That is why the effect of existing guidelines for creating easy-to-read text to websites was investigated. The 
European Commission had guidelines formulated for the production of easy-to-read information for people with intellectual disabilities, the Make it simple-guidelines (Freyhoff et al. 1998). These guidelines concern the verbal content and the layout of documents. Examples of Make it simple-guidelines are: use short sentences mostly, cover only one main idea per sentence, try to put one sentence on a line, use a maximum of two typefaces (see Appendix for a list of the guidelines). These guidelines were initially meant for texts on paper, but the majority can also be applied to websites. Comparable guidelines are formulated by other organizations, such as Mencap, the UK's learning disability charity (Mencap 2000).

The present research investigated whether the application of those Make it simple-guidelines would have a positive effect on the usability for users with intellectual disabilities. The focus of the study was on the guidelines regarding the verbal content of the website. Usability is defined as 'the extent to which [it] can be used by specified users to achieve specified goals with effectiveness, efficiency and satisfaction in a specified context of use', according to the International Organization for Standardization (ISO) (1998, p. 6). Therefore, the users' effectiveness and efficiency of information processing and their satisfaction with the website were measured.

However, accessibility for a specific group of users should not lead to the reduced accessibility for other groups of users. As WAI priority 1 checkpoint 11.4 indicates, creating multiple versions of the same site should only be a last resort. Therefore, it was also investigated whether application of the easy-to-read guidelines has a negative effect on the usability for website users without identified intellectual disabilities.

The remainder of this article describes an experiment that was conducted to investigate the effects of the guidelines for the production of easy-to-read information. Two versions of a website for a welfare and care organization were developed. This non-profit organization supports people with various disabilities, especially people with intellectual disabilities. In this experiment, the effects of two alternative versions of the organization's website for two groups of users were assessed by using a $2 \times 2$ between-subjects design. The two versions of the website contained the same information, but in one of the two versions the text was adapted by applying easy-to-read text guidelines rigorously. Each of the two versions was used by a group of test participants with intellectual disabilities and by a control group of participants without identified intellectual disabilities. Using this design, the appropriateness of verbal content created with easy-to-read guidelines for users with and without intellectual disabilities could be tested.

\section{Method}

\section{Participants}

Forty experienced computer users participated in the test of the appropriateness of the guidelines (23 female and 17 male, mean age 37 years). Twenty participants, 12 female and eight male, were clients of the care organization because of their intellectual disabilities. However, they could read, at least to a certain extent. Ten of them used the adapted version of the site (further referred to as the A-site) and the other 10 used the nonadapted site (NA-site). The other 20 participants had no identified intellectual disabilities. This group was known to be involved with people with intellectual disabilities as a parent, a friend or a partner. From this control group, 10 participants used the A-site and the other 10 used the NA-site.

All forty participants were frequent computer and Internet users: $90 \%$ of the participants used a computer at least once a week and $75 \%$ of them used the Internet at least once a week. Although the group of participants with intellectual disabilities on average had somewhat less computer experience than the control group (6 years against 10 years), they were all considered experienced users. The amount of computer experience as well as the readings skills proved to be evenly distributed across the groups who used the A-site and the groups who used the NA-site.

\section{Materials}

Two versions of a website with text in Dutch were created. This website consisted of a home page with an introduction and some general information about the care provider, and four other sections. The content was based on a leaflet that was written for the care provider organization, describing its main services and activities in standard well-written text. The non-adapted website (NA) contained the leaflet information. For the adapted site (A), the text was made easier to read on the basis of the easy-to-read guidelines (see Appendix). Figures 1 and 2 show parallel pages of the NA-site and the A-site.

Before the experiment, the adapted site was evaluated for its comprehensibility by a specialist in care for people with intellectual disabilities and a web communication expert. They checked whether the guidelines for easy-to-read text were applied correctly. In addition, 

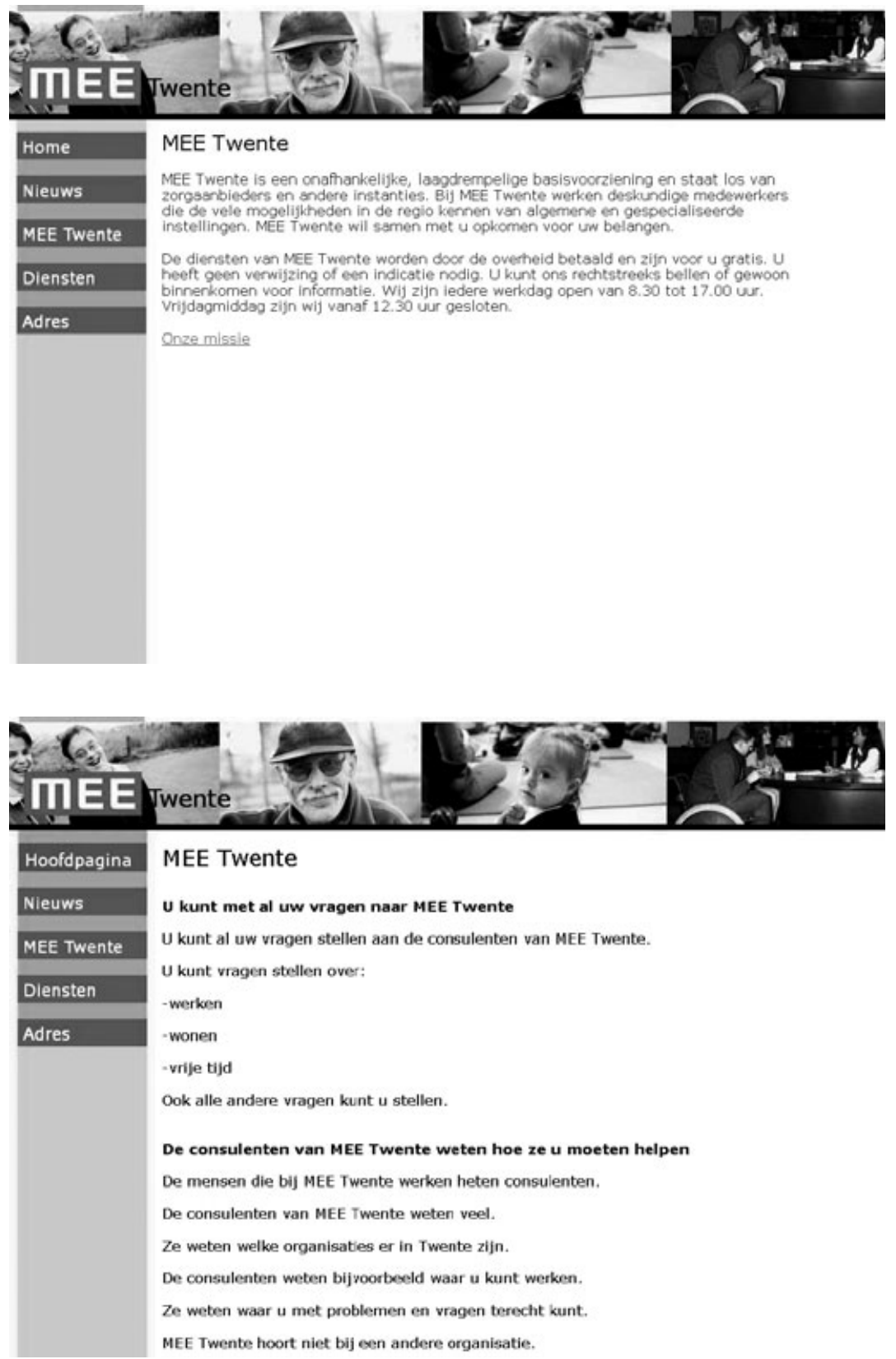

MEE Twente

U kunt met al uw vragen naar MEE Twente

u kunt al uw vragen stellen aan de consulenten van MEE Twente.

$U$ kunt vragen stellen over:

-werken

-wonen

-vrije tijd

Ook alle andere vragen kunt $u$ stellen.

De consulenten van MEE Twente weten hoe ze u moeten helpen

De mensen die biJ MEE Twente werken heten consulenten.

De consulenten van MEE Twente weten veel.

Ze weten welke organisaties er in Twente zijn.

De consulenten weten bijroorbeeld waar $u$ kunt werken.

Ze weten waar $\mathrm{u}$ met problemen en vragen terecht kunt.

MEE Twente hoort niet bij een andere organisatie.
Figure I Non-adapted version of the website. two people with intellectual disabilities used and evaluated the adapted version of the site. Based on the remarks of these four people, it was ensured that the Aversion of the website followed the easy-to-read guidelines closely.

\section{Measuring effectiveness and efficiency}

The two versions of the website were tested for efficiency (searching and reading time) and effectiveness
Figure 2 Adapted version of the website.

(comprehension). The participants were asked to execute five search tasks with the website version they were working with. They were asked, for example, to search for information about courses and discussion groups organized by the care provider. After they had found and read the correct page, they had to answer some questions about the content of the page. They answered 14 questions in total. Seven of these questions could be answered with information that could be found literally in the verbal content of the site (text-based questions). 
Figure 3 Satisfaction questionnaire.

For the other seven questions, the answer had to be deduced from information in the site (inference questions). The 14 questions were offered in two different formats. Eight of the questions were open questions; the other six were multiple-choice questions. The two formats were equally divided over text-based and inference questions.

A distinction was made between text-based and inference questions, because studies of reading processes have shown that making inferences requires a deeper form of processing and comprehension than just recognition of information (Kintsch 1988). The aim of using two types of questions was to see whether the adapted text increased comprehension of verbal content both at the recognition and the inference level. The variation in question format (open and multiple-choice) was inspired by a handbook on doing research with people with intellectual disabilities (Huizing et al. 2002). This book suggested that multiple-choice questions are easier for people with intellectual disabilities because they can recognize the correct answer among the alternatives. It was investigated whether the adapted text increased comprehension to an extent that participants with intellectual disabilities could formulate their own answers.

\section{Measuring satisfaction}

Satisfaction with the website was measured with an adapted and translated version of the validated Chen \& Wells (1999) instrument for measuring the attitude towards a website. This instrument consists of statements about the site used, on which the participants score on a five-point rating scale, ranging from definitely disagree (1) to definitely agree (5). The instrument is meant for measuring the attitude towards e-commerce websites. In this experiment, only those items were used that were applicable to informational websites, like the website of the care provider. Fourteen statements from the original instrument were translated into Dutch, taking care that the words used were easy to understand (see Figure 3).

\section{Procedure}

The participants executed the tasks with the website at their homes. The sessions took $40 \mathrm{~min}$, on average. The two versions of website were stored on hard disk on a laptop that the experimenter brought for the experiment. The participants were asked to read aloud during the tasks. Each session was recorded on videotape.

Instructions and explanation were introduced orally, to reduce the amount of reading required from the participants. Once a task was introduced by the experimenter, the participants started to search for the requested information on the website, followed by reading the requested information. The time needed for finding and reading the information was measured to compare the differences in efficiency between the A-site and the NA-site.

The experimenter offered assistance only after the participants expressed their inability to find the information more than two times. Her assistance consisted of a first question, asking the participants what they tried to achieve. Just asking that question in some cases was enough to overcome the problems. When this was not the case, the experimenter directed the participants to the page they had to visit. When the participants were on the correct page, no more assistance was given. The experimenter knew which participants had intellectual disabilities. Although she tried to act exactly the same with respect to every participant, it is possible that this knowledge influenced the number of times that she offered assistance to the participants.

When the participants had read the information, they returned to the home page. Then the experimenter posed the questions and wrote down the answers. The 
numbers of correct answers on the different types of questions were measured to find out whether the guidelines increased the comprehension or effectiveness of the site.

When the participants had completed the five tasks, they filled out the questionnaire that was used to measure satisfaction with the site. Again, the items in the questionnaire were read out by the experimenter, who also scored the answers.

\section{Results}

\section{Efficiency in seeking information}

As a measure of efficiency, the time needed for finding the correct information for each task was measured. However, the assistance that was offered to participants who could not find the requested information did interfere with time measurements, because in that case the experimenter directed the participants to the correct page.

Especially, the participants with intellectual disabilities had difficulties in finding the information. Fifteen (out of 20) needed assistance, varying from one to seven times. Ten (out of 20) participants without identified intellectual disabilities needed assistance, in all cases one or two times. The number of times that assistance was offered is shown in Table 1. The participants with intellectual disabilities needed obviously more assistance to complete the five tasks than the control group. Remarkably, the participants who used the A-website needed more assistance than the users of the NA-site. However, the differences between these groups were relatively small.

\section{Efficiency in reading the information}

Efficiency was also measured by comparing the time that the participants needed to read the requested

Table I Numbers of times that assistance was offered, total over five tasks

\begin{tabular}{lll}
\hline & A-website & NA-website \\
\hline $\begin{array}{l}\text { Participants with } \\
\text { intellectual disabilities }\end{array}$ & 25 & 17 \\
$\begin{array}{c}\text { Participants without identified } \\
\text { intellectual disabilities }\end{array}$ & 8 & 6 \\
\hline
\end{tabular}

A, adapted; NA, non-adapted.
Table 2 Mean reading times, total over five tasks

\begin{tabular}{lll}
\hline & A-website & NA-website \\
\hline $\begin{array}{l}\text { Participants with } \\
\text { intellectual disabilities }\end{array}$ & $511(110)$ & $547(121)$ \\
$\begin{array}{c}\text { Participants without identified } \\
\text { intellectual disabilities }\end{array}$ & $413(102)$ & $398(88)$ \\
\hline
\end{tabular}

A, adapted; NA, non-adapted. Time in seconds. SD between parentheses.

information. The number of words that had to be read to complete a particular task differed between the two versions of the site, but the total number of words that the participants had to read for the five tasks was almost equal: 886 words on the NA-website and 899 words on the A-website. Because of the differences in number of words at task level, only the total reading times of the participant groups were compared (see Table 2).

The participants with intellectual disabilities needed almost $9 \mathrm{~min}$ to read the text on the website. On average, the participants without intellectual disabilities needed less than $7 \mathrm{~min}$. This difference is statistically significant, as shown by the results of a parametric two-way ANova $\left[F(1,36)=13.57 ; P<0.01 ; \eta^{2}=0.27\right]^{1}$. The reading time was not influenced by the version of the website, as the ANOva showed $[F(1,36)<1]$. In addition, the ANOVA showed no interaction between the two factors (website version, participant group): $F(1,36)<1$.

A clear conclusion can be drawn regarding the efficiency of reading verbal content, which is adapted to the needs of people with intellectual disabilities that influence language competence. People with those disabilities need more time to read the text than a control group of people without identified intellectual disabilities, even when that text is easy-to-read. They also need more help to find the pages in a site, again also when the verbal content is adapted to their needs.

\footnotetext{
${ }^{1}$ Non-parametric tests are more appropriate for analysing the results of this experiment than parametric tests because of the small number of participants. However, non-parametric tests are not suitable for measuring interactions between variables. Therefore, both non-parametric Mann-Whitney tests and parametric ANOvas were applied. In all cases, the findings of the two test methods confirmed each other. Only the results of the analyses of variance are reported.
} 


\section{Effectiveness: comprehending the information in the site}

The effectiveness of the website was measured in two ways. First, the participants answered 14 questions about the information they had read. Their answers reflected the degree of comprehension. The mean numbers of correct answers on the questions are depicted in Table 3. Over all, the participants with intellectual disabilities answered fewer questions correctly than the control group of participants without identified disabilities. The participants who used the A-website answered more questions correctly than the participants who used the NA-website. The results of a two way ANOvA showed that these differences are significant: $F(1,36)=24.80 ; P<0.001 ; \eta^{2}=0.41$ and $F(1,36)=12.56$; $P<0.01 ; \eta^{2}=0.26$. The same analysis showed no interaction between the factors website and participant group: $F(1,36)<1$. So the adaptation of the site helped increase comprehension, both for the participants with intellectual disabilities and for the participants without intellectual disabilities.

The level of comprehension required to answer the questions was varied. Half of the questions were textbased: the answer could be found literally in the text read. A two-way ANOva that included only these seven text-based questions showed the same pattern as observed above. The participants with intellectual disabilities answered fewer questions correctly than the control group without identified intellectual disabilities: $F(1,36)=8.15 ; P<0.01 ; \eta^{2}=0.19$. The participants who used the adapted website answered more questions correctly than the participants who used the non-adapted website: $F(1,36)=19.71 ; P<0.01 ; \eta^{2}=0.35$. Again, no interaction was found: $F(1,36)<1$. Therefore, with regard to text-based questions, it can be concluded that

Table 3 Mean numbers of correct answers, by question type

\begin{tabular}{lrr}
\hline & A-website & NA-website \\
\hline Participants with intellectual disabilities \\
Text-based questions (7) & $5.40(1.08)$ & $4.30(1.42)$ \\
Inference questions (7) & $3.85(1.25)$ & $2.60(0.78)$ \\
Total & $9.25(2.12)$ & $6.90(1.88)$ \\
Participants without identified intellectual disabilities \\
Text-based questions (7) & $6.60(0.52)$ & $4.90(0.74)$ \\
Inference questions (7) & $5.05(1.14)$ & $5.15(0.97)$ \\
Total & $11.65(1.40)$ & $10.05(1.55)$ \\
\end{tabular}

A, adapted; NA, non-adapted. SD between parentheses. the adaptation of the site increased comprehensibility for both groups of participants.

The other half of the questions could only be answered correctly by making inferences. An ANOvA that included these seven inference questions showed different results. As in the previous analyses, the participants with intellectual disabilities answered fewer questions correctly than the participants without identified intellectual disabilities: $\quad F(1,36)=31.90 ; \quad P<0.01$; $\eta^{2}=0.47$. However, the difference between the websites was not significant: $F(1,36)=3.00 ; P=0.09$. A significant interaction effect was found: $F(1,36)=4.13$; $P<0.05 ; \eta^{2}=0.10$, and therefore the two versions were tested against each other within the two participant groups with $t$-tests. Participants with intellectual disabilities who read the content of the adapted website answered more inference questions correctly than those who read text in the non-adapted website: $t=2.69$, d.f. $=18, P<0.05$. The version of the website had no effect on the number of correctly answered inference questions by participants without intellectual disabilities: $t<1$. It can be concluded that, with regard to inference questions, the adaptation of the site increased comprehensibility for participants with intellectual disabilities.

Over all, readers without identified intellectual disabilities comprehended the information better than readers with intellectual disabilities, as one can expect, but comprehension increased considerably for readers with intellectual disabilities, when the verbal content of the site was adapted. This effect was strong, and occurred both when they expressed their comprehension in textbased questions and in inference questions. There is no negative effect for participants without identified disabilities when they answer inference questions and a positive effect when they answer text-based questions. So, the control group benefited also from reading the easy-to-read text in the adapted website, although to a lesser extent than the group of participants with intellectual disabilities.

The format of the questions was also varied. Six questions were multiple-choice questions and the other eight questions were open questions. Table 4 shows the number of correctly answered multiple-choice questions and open questions. The participants with intellectual disabilities answered fewer multiple choice and fewer open questions correctly: $F(1,36)=27.73 ; P<0.001 ; \eta^{2}=0.44$ and $F(1,36)=12.21 ; P<0.01 ; \eta^{2}=0.25$. The version of the website did not affect the number of correctly answered multiple-choice questions: $F(1,36)=1.62$; $P>0.10$. However, the version of the website did affect 
Table 4 Mean numbers of correct answers, by question format

\begin{tabular}{|c|c|c|}
\hline & A-website & NA-website \\
\hline \multicolumn{3}{|c|}{ Participants with intellectual disabilities } \\
\hline Multiple-choice questions (6) & $4.20(1.03)$ & $4.00(1.25)$ \\
\hline Open questions (8) & $5.05(1.34)$ & $2.90(1.10)$ \\
\hline Total & $9.25(2.12)$ & $6.90(1.88)$ \\
\hline \multicolumn{3}{|c|}{ Participants without identified intellectual disabilities } \\
\hline Multiple choice questions (6) & $5.80(0.42)$ & $5.30(0.48)$ \\
\hline Open questions (8) & $5.85(1.18)$ & $4.75(1.16)$ \\
\hline Total & $11.65(1.40)$ & $10.05(1.55)$ \\
\hline
\end{tabular}

A, adapted; NA, non-adapted. SD between parentheses.

the number of correctly answered open questions: $F(1,36)=18.36 ; \quad P<0.001 ; \quad \eta^{2}=0.34$. No interactions between the participant groups and the versions of the website were found: $F(1,36)<1$ (multiple choice questions), $F(1,36)=1.92 ; P>0.10$ (open questions).

These results indicate that adapting websites using the easy-to-read guidelines increased the comprehension of the text for text-based questions and, for participants with intellectual disabilities, also for inference questions. Furthermore, open questions seem more appropriate for demonstrating these differences, which were not visible in the multiple-choice questions.

\section{Analysis of reading errors}

The transcripts of the recordings of the participants offered insight in their reading difficulties. The reading errors that the participants made during reading-aloud the pages of the website were analysed, assuming that they could reveal comprehension problems. The transcripts of the recordings showed that the participants did not read the text flawlessly (see Table 5). The most common error was that words were pronounced incorrectly, which resulted in reading non-existing words. Although this does not automatically imply that the participants did not understand the meaning of the word, it might indicate that they experienced a problem. Words that were typically pronounced incorrectly were long words, foreign words and loan words. Another type of error that was regularly observed is replacing a word by another existing word with a different meaning, for example replacing difficult by different. This type of error seemed to have a more negative impact on comprehension.

Participants with intellectual disabilities made many more errors (188) than the control group of participants
Table 5 Mean number and type of errors during readingaloud

\begin{tabular}{lll}
\hline & A-website & NA-website \\
\hline $\begin{array}{l}\text { Participants with intellectual disabilities* } \\
\text { Incorrect pronunciation of words }\end{array}$ & 17 & 59 \\
Replacement of one word by another & 27 & 85 \\
Participants without identified intellectual disabilities \\
Incorrect pronunciation of words \\
Replacement of one word by another
\end{tabular}

without identified intellectual disabilities (59). More important, participants with intellectual disabilities who worked with the non-adapted website made more errors (144) than their peers who worked with the adapted website (44). This is an additional evidence that the text on the adapted website was easier to read than the text on the non-adapted website.

Although no significant difference was found between the reading times (efficiency) of the two versions, clear differences were observed in the effectiveness of the adapted site compared with the non-adapted site. Readers with intellectual disabilities that affected their reading competence made more comprehension errors than readers without identified intellectual disabilities. However, the performance of the participants with intellectual disabilities improved when they read the information from the adapted site. They answered more questions correctly and made far fewer reading errors. Participants without identified intellectual disabilities were not negatively affected by the adapted site. They performed at a similar level as the participants who used the non-adapted site, or outperformed them when answering text-based questions.

\section{Satisfaction with the site}

The satisfaction of the participants with the website version they had been using was tested by asking them to express their opinions on a 14-item questionnaire. Whatever version of the site participants had been using, they evaluated it positively. The mean scores on the separate items were rather high, varying from 2.8 to 4.8 on a 5-point scale (with 5 being the most positive answer). 
Table 6 Satisfaction with the site $(1=$ negative, $5=$ positive $)$

\begin{tabular}{lll}
\hline & A-website & NA-website \\
\hline $\begin{array}{c}\text { Participants with } \\
\text { intellectual disabilities }\end{array}$ & $4.25(0.52)$ & $3.94(0.44)$ \\
$\begin{array}{c}\text { Participants without special } \\
\text { intellectual disabilities }\end{array}$ & $3.83(0.76)$ & $4.24(0.49)$ \\
\hline
\end{tabular}

A, adapted; NA, non-adapted. SD between parentheses.

The satisfaction scales used in the questionnaire were highly reliable $(\alpha=0.89)$.

The scores on one item, derived from the original Chen and Wells questionnaire, differed from all others. It read: compared to other websites, I would rate this one as one of the worst (1) ... one of the best (5). This question required comparing the website just used with other sites. Also, the scoring options did not run from definitely disagree to definitely agree, as in all other items. On this particular item, 32 of our 40 participants scored a neutral 3, expressing that for them the site used was neither worse nor better than other websites. Whatever their reasons for this atypical answer, the item did not discriminate between participants, and therefore was removed from the analysis. This did not reduce the reliability $(\alpha=0.88)$. Table 6 shows the mean scores for satisfaction, measured over 13 items.

A two-way ANOva showed no significant difference between the mean scores of the two participant groups and between the mean scores of the two versions of the website, in both cases: $F(1,36)<1$. However, there was a significant interaction effect: $F(1,36)=4.06, P=0.05$, $\eta^{2}=0.10$. Participants with intellectual disabilities preferred the adapted website while participants without identified intellectual disabilities preferred the nonadapted website. In other words: each group liked the website best that was geared to their reading and intellectual levels.

\section{Conclusions}

The study reported was conducted in order to investigate whether a rather unspecific WAI guideline (use the clearest and simplest language appropriate for a site's content) could be substantiated with more detailed instructions on how to adapt the verbal content of a site. Existing guidelines that were formulated by the European Commission (Freyhoff et al. 1998) were used for writing easy-to-read text as the elaboration of the unspecific guideline.
In terms of efficiency (searching and reading time), the application of the guidelines did not have any positive effects. Almost no differences were observed between the two versions of the site. Participants with intellectual disabilities needed more time to read the text than the control group of participants without identified intellectual disabilities. Moreover, the participants with intellectual disabilities needed more assistance to find the information they were looking for.

In terms of effectiveness, the adaptation of the verbal content worked well for readers with intellectual disabilities. They understood the verbal content better, as was demonstrated in an increased number of questions about the content answered correctly. The group of users with intellectual disabilities who worked with the easy-to-read version of the site even approached the achievements of the control group of users without identified intellectual disabilities who worked with the non-adapted site. Also, the participants with intellectual disabilities made far fewer reading errors when reading the text of the adapted site. It can be safely concluded that the text adaptation worked well for its target group: users who have intellectual or language disabilities.

Users without identified intellectual disabilities were as effective with the adapted site as they were with the non-adapted site, except for questions for which the answer could be found literally in the text. For that category of questions, the adapted site worked better for them than the non-adapted site. It appears that text adaptation did not hurt our control group of readers. Yet, they expressed that they were less satisfied with the adapted site. They preferred the non-adapted site over the adapted site, whereas the readers with intellectual disabilities expressed their preference for the adapted site. This negative assessment of satisfaction should weigh even stronger considering who were included in our control group: friends, parents and partners of people with intellectual disabilities, who were familiar with the care provider that ran the website.

Because of the preference of our control group for the non-adapted version, a conditional recommendation to those organizations that consider adapting the verbal content of their websites seems appropriate. The results of this study lead to the advice to adapt the text using existing easy-to-read guidelines such as those of Freyhoff $e t$ al. (1998). Site visitors with language and intellectual disabilities will benefit from the adaptation. However, in order not to alienate non-disabled visitors of the site, it might be a good idea to make it clear upfront why the site is adapted: to serve the needs of a 
particular part of the visiting public. In addition, the creation of a site with a carefully attuned mix of adapted and non-adapted verbal content could be considered. Information which is visible at high-level pages could be made easy-to-read, with links to more specific, non-adapted information for those who want to know and read more.

A final conclusion from our study concerns the relevance of testing the content of a site with people from the target audience, in our case the audience of user with intellectual disabilities. Designers and writers of verbal site content can assure that they have met the WAI guideline about the clearest and simplest language only by involving test participants with intellectual or language disabilities. They are the ones who can give advice about whether the language in the site was clear and simple enough.

\section{Correspondence}

Any correspondence should be directed to Joyce Karreman, Department of Professional and Technical Communication, Faculty of Behavioural Sciences, University of Twente, P.O. Box 217, 7500 AE Enschede, The Netherlands (e-mail: j.karreman@utwente.nl).

\section{References}

Chen Q. \& Wells W. D. (1999) Attitude toward the site. Journal of Advertising Research 39, 27-37.

Freyhoff G., Hess G., Kerr L., Menzel E., Tronbacke B. \& Van der Veken K. (1998) Make It Simple, European Guidelines for the Production of Easy-to-Read Information for People with Learning Disability. ILSMH European Association, Brussels.

Huizing A. R., Maaskant M. A., Hamers J. P. H. \& Groot W. (2002) Een eigen invulling. Zorgbehoeften van mensen met een verstandelijke handicap. [Needs for Care of People with Cognitive Disabilities]. Universitaire Pers Maastricht, Maastricht.

International Organization for Standardization (ISO). (1998) International Standard ISO 9241-11: Ergonomic Requirements for Office Work with Visual Display Terminals (VDTs) - Part 11: Guidance on Usability. ISO, Geneva, Switzerland.

Kintsch W. (1988) The role of knowledge in discourse comprehension: a construction-integration model. Psychological Review 95, 163-182.

Mencap. (2000) Am I making myself clear? Mencap's guidelines for accessible writing. http://www.mencap.org.uk/download/ making_myself_clear.pdf (Accessed on 6 June 2006).

W3C Web Accessibility Initiative guidelines. (1999) http:// www.w3.org/TR/1999/WAI-WEBCONTENT-19990505/fullchecklist (Accessed on 6 June 2006).

\section{Appendix}

Make it simple guidelines

Verbal content of documents

- Use simple, straightforward language.

- Avoid abstract concepts.

- Use short words of everyday spoken language.

- Use many personal words.

- Use practical examples.

- Address the readers in a respectful form.

- Use short sentences only.

- Cover only one main idea per sentence.

- Use positive language.

- Use active rather than passive verbs.

- Do not assume previous knowledge about your subject.

- Use words consistently.

- Keep the punctuation simple.

- Do not use the subjunctive tense.

- Be careful with figures of speech and metaphors if they are not very common.

- Be careful with numbers.

- Do not use words from other languages.

- Avoid cross references.

- Mention a contact address for further information if possible.

Layout of documents

- Never use a picture as background for the text.

- Try to put one sentence on one line.

- Keep sentences together on one page.

- The paper should be matt and of good quality.

- Do not fill your page with too much information.

- Use a maximum of two typefaces.

- Use clear typefaces.

- Use a large type-size.

- Be careful about how you emphasize text.

- Make sure illustrations are in a sharp focus.

- Never use inverted printing (light text on a dark background).

- Use colours for picture, boxes, etc. if possible.

- Use headings and other 'navigational aids'.

- Numbers. For dates, use the full format. Telephone numbers should be separated. Always use the numeral and not the equivalent word. Never use roman numerals.

- Do not justify the text on the right hand side.

- Do not hyphenate long words at the right margin of the text. 